\title{
Household transmission of haemolytic uraemic syndrome associated with Escherichia coli O104:H4, south-western France, June 2011
}

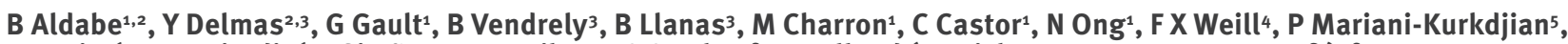

F Terrier ${ }^{6}$, M Desjardin' ${ }^{6}$, S Simões, B Le Bihan ${ }^{7}$, C Combe3,8, P Rolland (Patrick.ROLLAND@ars.sante.fr) ${ }^{1,8}$

1. French Institute for Public Health Surveillance (Institut de Veille Sanitaire; InVS), Regional office 'Cire Aquitaine', Bordeaux, France

2. These authors contributed equally to this work

3. Bordeaux University Hospital, Bordeaux, France

4. Institut Pasteur, National Reference Centre for Escherichia coli and Shigella, Paris, France

5. Robert Debré Hospital, Associated Laboratory to the National Reference Centre for Escherichia coli and Shigella, Paris, France

6. Robert Picqué Military Hospital, Villenave-D’Ornon, France

7. Regional Health Agency of Aquitaine, Bordeaux, France

8. Both authors contributed equally to this work

Citation style for this article:

Aldabe B, Delmas Y, Gault G, Vendrely B, Llanas B, Charron M, Castor C, Ong N, Weill FX, Mariani-Kurkdjian P, Terrier F, Desjardin M, Simões J, Le Bihan B, Combe C, Rolland P. Household transmission of haemolytic uraemic syndrome associated with Escherichia coli O104:H4, south-western France, June 2011.

Euro Surveill. 2011;16(31):pii=19934. Available online: http://www.eurosurveillance.org/ViewArticle.aspx?Articleld=19934

Following the outbreak of haemolytic uraemic syndrome (HUS) on June 2011 in south-western France, household transmission due to Escherichia coli 0104: $\mathrm{H}_{4}$ was suspected for two cases who developed symptoms 9 and 10 days after onset of symptoms of the index case. The analysis of exposures and of the incubation period is in favour of a secondary transmission within the family. Recommendations should be reinforced to prevent person-to-person transmission within households.

\section{Introduction}

On 30 June 2011, an outbreak of haemolytic uraemic syndrome (HUS) and bloody diarrhoea was reported among attendees of an open day event at a children's community centre that took place on 8 June in a town near Bordeaux, south-western France [1]. The identified strain was Shiga toxin 2-producing Escherichia coli $0_{104}: \mathrm{H}_{4}$, with the same characteristics as the strain that caused the recent outbreak in Germany [2,3,4]. As of 26 July 2011, 15 cases of bloody diarrhoea have been observed in relation with this event, nine of whom have developed HUS. An investigation was conducted to identify the vehicles of infection and to guide control measures. Preliminary results of interviews and trawling questionnaires suggested sprouts as the vehicle of transmission. Here we describe the two cases of HUS for whom household transmission of E. coli $\mathrm{O}_{104}: \mathrm{H}_{4}$ was suspected. The possibility of person-to-person transmission of $E$. coli 0104: $\mathrm{H}_{4}$ has also been reported in the Netherlands [5].

\section{Case descriptions}

\section{Patient A}

On 18 June, a man in his 40 s was admitted in a hospital near Bordeaux, with abdominal pain and bloody diarrhoea of two days. Stool samples were sent to the National Reference Centre for $E$. coli and Shigella in Paris. Four days after admission, the patient left the hospital and returned home. On 27 June, he was hospitalised again in the nephrology department of Bordeaux University Hospital with a diagnosis of HUS. Test results from stool samples showed the presence of $E$. coli 0104: $\mathrm{H}_{4}$ possessing the st 22 gene, encoding Shiga toxin 2. The strain was negative for the gene coding for intimin (eae) but positive for aggR which regulates the expression of aggregative adherence fimbriae. The antimicrobial resistance pattern of the strain was similar to than seen in the outbreak strain in recent $E$. coli $0_{104}: \mathrm{H}_{4}$ outbreak in Germany: ampicillin-resistant (R), cefotaxime- $R$, ceftazidime-R, imipenem-sensitive (S), streptomycin-R, kanamycin-S, gentamicin-S, sulfamethoxazole-R, trimethoprim- $R$, cotrimoxazole- $R$, tetracycline- $R$, chloramphenicol-S, nalidixic acid-R, and ciprofloxacin- $R$. The $P C R$ analysis indicated the presence of the bla $a_{\text {CTX-M-15 }}$ gene, encoding an extended-spectrum beta-lactamase (ESBL), and the presence of the bla $a_{\mathrm{TEM}}$ gene, encoding a penicillinase. After treatment, the patient gradually recovered from HUS. He returned home on 6 July having received specific hygiene guidelines from the hospital, notably recommendations about hand-washing.

Patient $A$ had participated in the open day event on 8 June, accompanied by his three-year-old child (Patient $B)$. His wife and his second five-year-old child did not attend. Patient A's interview revealed that he had consumed three kinds of sprouts (fenugreek, mustard, and rocket) during the event.

\section{Patient B}

The three-year-old child of Patient A presented first symptoms of illness on 26 June, i.e. 18 days after the 
open day and nine days after the onset of symptoms in Patient A. At onset, the child had abdominal pain followed after three days by bloody diarrhoea. Shiga toxin 2-producing E. coli $0104: \mathrm{H}_{4}$ was isolated from stool samples. Some bacterial colonies produced the ESBL, whereas others only the penicillinase. However, both types of colonies were also resistant to streptomycin, sulfamethoxazole, trimethoprim, cotrimoxazole, tetracycline, and nalidixic acid, as observed for other outbreak isolates [1]. On 3 July, the child developed anaemia, haemolysis and high urine protein-tocreatinine ratio, compatible with HUS and was admitted to the paediatric department of Bordeaux University Hospital. On 4 July, thrombocytopenia developed. The child gradually recovered after treatment and was discharged from hospital on 8 July.

Patient $B$ had participated in the open day event but, according to Patient $A$, did not consume sprouts. As the children had no access to the buffet unless accompanied by an adult, it is unlikely that the child has eaten any sprouts without the father's knowledge.

\section{Patient C}

On 2 July, a woman in her 30s, wife of Patient $A$ and mother of Patient B, was admitted to Bordeaux University Hospital with bloody diarrhoea of six days, i.e. she had had the first signs of disease on 27 June, respectively 10 and 1 days after the onset of illness in Patient A and Patient B. Shiga toxin 2-producing E. coli $\mathrm{O}_{104}: \mathrm{H}_{4}$ was isolated from her stool samples. It was resistant to ampicillin, streptomycin, sulfamethoxazole, trimethoprim, cotrimoxazole, tetracycline, and nalidixic acid, but susceptible to extended-spectrum cephalosporins (i.e. only production of the penicillinase). The absence of the CTX-M-15 ESBL compared to the isolates from Patient $A$ and some isolates from Patient $B$ might be due to the mobilisation of insertion sequences usually present in the vicinity of the bla $a_{\text {CTX-M-15 }}$ gene. This might be in relation to the absence of selective pressure by this class of antimicrobials. Patient $\mathrm{C}$ developed symptoms of anaemia, haemolysis, thrombocytopenia and proteinuria on 8 July. After treatment, she recovered gradually and she left the hospital on 12 July.

Patient $C$ had not attended the open day event and not consumed any type of sprouts during the two months previously.

\section{Family members}

The five-year-old child spent the whole period at home. It did not develop any symptoms but was admitted to the paediatric department of Bordeaux University Hospital for observation from 3 to 4 July.

Two other relatives of Patients $A, B$ and $C$ shared meals in the family's house on 26 June. One of them stayed in the family's house between 29 June and 3 July and complained of severe fatigue. The other relative developed mild diarrhoea on 28 June. A rectal swab was performed for both with an 0104 serology for the relative with severe fatigue. Both relatives' stool samples were negative for the presence of $E$. coli $\mathrm{O}_{104}: \mathrm{H}_{4}$.

\section{Hypothesis of transmission}

We hypothesised that Patients B and C both probably acquired HUS by secondary transmission from Patient $A$ because they developed illness 9 and 10 days, respectively, after Patient A's symptom onset.

\section{FIGURE}

Two cases of probable household transmission of haemolytic uraemic syndrome due to Escherichia coli O104:H4, southwestern France, June 2011

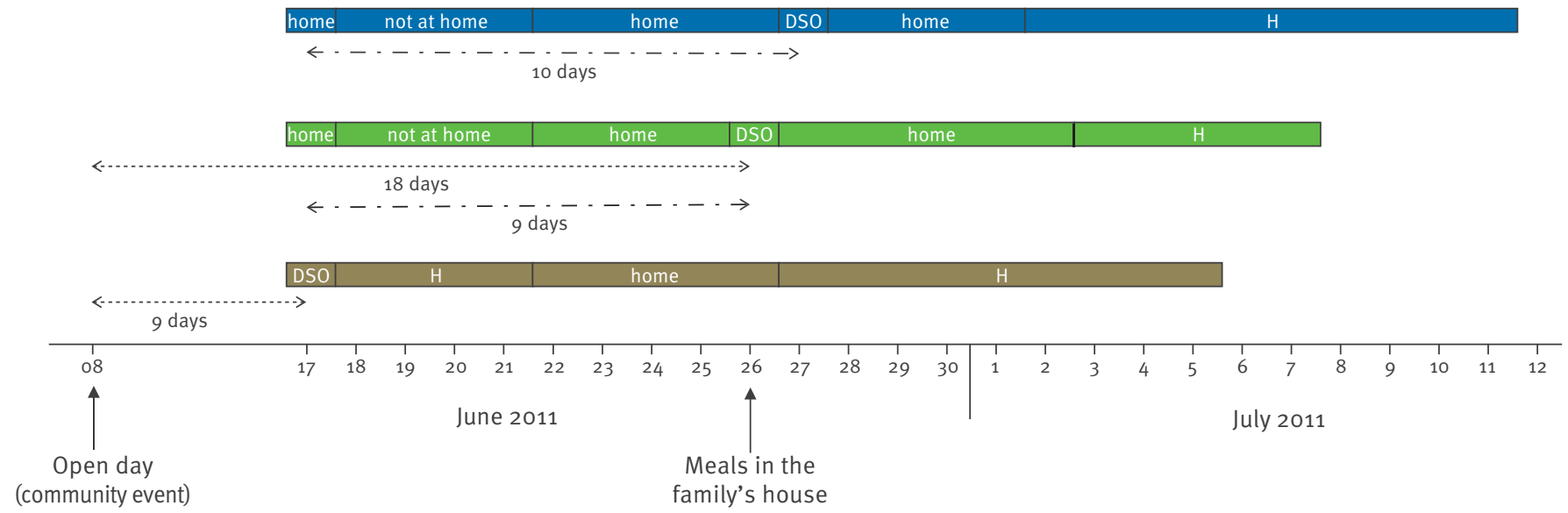

$\square$ Patient C $\square$ Patient B $\square$ Patient A (index case)

$\leftrightarrow-\rightarrow$ Time period between open day and DSO of Patients A and B (who attented the open day).

$\leftarrow>$ Time period between DSO of Patient A (index case) and Patients B and C

DSO: date of symptom onset; $\mathrm{H}$ : hospitalised (the day of discharge was not counted as day of hospitalisation). 
Although Patient B attended the open day event, food-borne transmission from the sprouts to patient $B$ is unlikely because she reportedly did not eat any sprouts. Moreover, an incubation period of 18 days would be unusually long. Both Patients $B$ and $C$ had spent time with Patient $A$ on the day when he first experienced symptoms and after his return from hospital. During his first hospitalisation, his family did not stay in Bordeaux and had no contact with him.

A recent study by the German outbreak investigation team showed that the median incubation period of $E$. coli $\mathrm{O}_{104}: \mathrm{H}_{4}$ in that outbreak was eight days (interquartile range: 7-9 days) [3]. Therefore, two scenarios can be considered for the household described here: transmission on 17 June when Patient A first presented symptoms at home, or transmission between 22 and 26 June after his return from hospital. Between 22 and 26 June, patient A had symptoms of diarrhoea and severe fatigue; during this period, he had prepared some meals.

\section{Recommendations for hygiene and infection control}

Following the detection of the outbreak on 22 June 2011, recommendations for hygiene and infection control were disseminated, starting on 24 June, to the general population and to the participants of the open day through several press releases, the website of the Ministry of Health, and local physicians. Furthermore, following the probable household transmission described here, a letter was sent on 5 July to the participants of the open day. This letter stressed the importance of personal hygiene measures, and safe food preparation practices, to reduce the risk of transmission. No other secondary cases in connection with the community event have been reported to date.

Here, as in the household transmission of $E$. coli 0104: $\mathrm{H}_{4}$ reported in the Netherlands [5], the index case was an adult. In our episode, one of the two secondary cases was also an adult. A review of 90 confirmed outbreaks caused by classical $E$. coli 0157 , showed that a lower median age of the index case was associated with a higher rate of secondary cases and that young children were most likely to become infected [6]. The unusual transmission from adult to adult observed in our episode is in line with the preponderance of cases in adults reported in the German outbreak [3]. This unusual pattern could be attributable to the specific properties of this strain $[4,7]$. Measures to prevent secondary transmission among adults should be strictly implemented.

Acknowledgements

We thank $\mathrm{N}$ Jourdan, $\mathrm{V}$ Vaillant and $\mathrm{H}$ de Valk for comments on the manuscript.

Agreement of patients

Written consent of patients to this report has been obtained.
References

1. Gault G, Weill FX, Mariani-Kurkdjian P, Jourdan-da Silva N, King $L$, Aldabe B, et al. Outbreak of haemolytic uraemic syndrome and bloody diarrhoea due to Escherichia coli $0104: \mathrm{H}_{4}$, southwest France, June 2011. Euro Surveill. 2011;16(26):pii=19905. Available from: http://www.eurosurveillance.org/ViewArticle. aspx?Articleld $=19905$

2. Frank C, Faber MS, Askar M, Bernard H, Fruth A, Gilsdorf A, et al. Large and ongoing outbreak of haemolytic uraemic syndrome, Germany, May 2011. Euro Surveill. 2011;16(21): pii=19878. Available from: http://www. eurosurveillance.org/ViewArticle.aspx?Articleld=19878

3. Frank C, Werber D, Cramer JP, Askar M, Faber M, Heiden MA, et al. Epidemic Profile of Shiga-Toxin-Producing Escherichia coli $\mathrm{O}_{104}: \mathrm{H}_{4}$ Outbreak in Germany - Preliminary Report. N Engl J Med. 22 Jun 2011 [Epub ahead of print]. doi:10.1056/ nejmoa1106483.

4. Bielaszewska M, Mellmann A, Zhang W, Köck R, Fruth A, Bauwens A, et al. Characterisation of the Escherichia coli strain associated with an outbreak of haemolytic uraemic syndrome in Germany, 2011: a microbiological study. Lancet Infect Dis. 23 Jun 2011 [Epub ahead of print]. doi:10.1016/ S1473-3099(11)70165-7.

5. Kuijper E J, Soonawala D, Vermont, van Dissel J T. Household transmission of haemolytic uraemic syndrome associated with Escherichia coli $0_{104}: \mathrm{H}_{4}$ in the Netherlands, May 2011. Euro Surveill. 2011;16(25):19897. Available from: http://www. eurosurveillance.org/ViewArticle.aspx?Articleld=19897

6. Snedeker KG, Shaw DJ, Locking ME, Prescott RJ. Primary and secondary cases in Escherichia coli 0157 outbreaks: a statistical analysis. BMC Infect Dis. 2009;9:144.

7. Mellmann A, Harmsen D, Cummings CA, Zentz EB, Leopold SR, Rico A, et al. Prospective genomic characterization of the German enterohemorrhagic Escherichia coli $0_{104}: \mathrm{H}_{4}$ outbreak by rapid next generation sequencing technology. Plos One. 2011;6(7):e22751. 